\title{
Sedentary behaviour among general practitioners: a systematic review
}

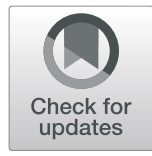

Richard S. Mayne ${ }^{1,2^{*}}$ D, Nigel D. Hart ${ }^{1}$ and Neil Heron²

\begin{abstract}
Background: Sedentary behaviour is when someone is awake, in a sitting, lying or reclining posture and is an independent risk factor for multiple causes of morbidity and mortality. A dose-response relationship has been demonstrated, whereby increasing sedentary time corresponds with increasing mortality rate. This study aimed to identify current levels of sedentary behaviour among General Practitioners (GPs), by examining and synthesising how sedentary behaviour has been measured in the primary care literature.

Methods: A systematic review was conducted to identify studies relating to levels of sedentary behaviour among

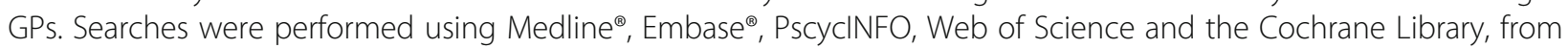
inception of databases until January 2020, with a subsequent search of grey literature. Articles were assessed for quality and bias, with extraction of relevant data.

Results: The search criteria returned 1707 studies. Thirty four full texts were reviewed and 2 studies included in the final review. Both were cross-sectional surveys using self-reported estimation of sedentary time within the International Physical Activity Questionnaire (IPAQ). Keohane et al. examined GP trainees and GP trainers in Ireland. $60 \%$ reported spending in excess of $7 \mathrm{~h}$ sitting each day, $24 \%$ between 4 and $7 \mathrm{~h}$, and $16 \%$ less than or equal to 4 h. Suija et al. examined female GPs in Estonia. The mean reported daily sitting time was $6 \mathrm{~h}$ and 36 min, with 56\% sitting for over $6 \mathrm{~h}$ per day. Both studies were of satisfactory methodological quality but had a high risk of bias.

Conclusion: There is a paucity of research examining current levels of sedentary behaviour among GPs. Objective data is needed to determine GPs' current levels of sedentary behaviour, particularly in light of the increase in remote consulting as a result of the COVID-19 pandemic.
\end{abstract}

Keywords: General practice, Primary care, Sedentary behaviour, Systematic review, Physical activity

\section{Background}

Sedentary behaviour is when someone is awake, in a sitting, lying or reclining posture, in a state of low energy expenditure, typically expending less than 1.5 metabolic equivalent of tasks (METs) [1, 2]. METs allow comparisons to be made between the energy expended during different states [3]. METs are calculated as a ratio of the rate of energy expended during an activity compared to

\footnotetext{
* Correspondence: rmayne02@qub.ac.uk

${ }^{1}$ Centre for Medical Education, School of Medicine, Dentistry and Biomedical Sciences, Queen's University Belfast, Belfast, UK

${ }^{2}$ Centre for Public Health, School of Medicine, Dentistry and Biomedical

Sciences, Queen's University Belfast, Belfast, UK
}

the rate of energy expended at rest [3]. For example, 1.0 METs is the rate of energy expenditure while sitting at rest [3]. A 2.0 METs activity, such as ironing, expends twice the energy used by the body when sitting at rest [3]. Physical activity is any movement of the body produced by skeletal muscles that requires energy expenditure [4]. Physical activity can therefore be viewed as a spectrum, ranging from sedentary behaviour to light, moderate and vigorous physical activity (Fig. 1.). Physical inactivity is a separate entity, instead defined as when an individual has insufficient levels of physical activity, i.e. less than current physical activity recommendations $[2,5]$.

C The Author(s). 2021 Open Access This article is licensed under a Creative Commons Attribution 4.0 International License, which permits use, sharing, adaptation, distribution and reproduction in any medium or format, as long as you give appropriate credit to the original author(s) and the source, provide a link to the Creative Commons licence, and indicate if changes were made. The images or other third party material in this article are included in the article's Creative Commons licence, unless indicated otherwise in a credit line to the material. If material is not included in the article's Creative Commons licence and your intended use is not permitted by statutory regulation or exceeds the permitted use, you will need to obtain permission directly from the copyright holder. To view a copy of this licence, visit http://creativecommons.org/licenses/by/4.0/ The Creative Commons Public Domain Dedication waiver (http://creativecommons.org/publicdomain/zero/1.0/) applies to the data made available in this article, unless otherwise stated in a credit line to the data. 


\section{Spectrum of Physical Activity}

$\begin{array}{cccc}\text { Sedentary } & \text { Light } \longrightarrow \text { Moderate } & \text { Vigorous } \\ <1.5 & 1.5-3.0 & 3.0-6.0 & >6.0 \\ \text { METs } & \text { METs } & \text { METs } & \text { METs }\end{array}$

Fig. 1 Spectrum of physical activity

The effect of sedentary behaviour on health has been an area of interest among researchers since the pioneering work of the epidemiologist, Jeremy Morris, in the 1940s and 1950s. Morris and colleagues demonstrated that sedentary bus drivers had higher rates of mortality due to coronary heart disease than bus conductors, their more active colleagues [6, 7]. Since then, there has been an ever-increasing weight of evidence to demonstrate the negative health effects of sedentary behaviour [8]. It is now acknowledged that sedentary behaviour is associated with multiple adverse health outcomes, including mental health issues, obesity, type 2 diabetes, multiple forms of cardiovascular disease and dementia, as well as breast, colorectal, endometrial and ovarian cancer [8-12]. As a result of these adverse health outcomes, sedentary behaviour is associated with increased all-cause mortality, even when allowing for confounding variables [12-15]. These findings demonstrate a dose-response relationship, whereby increasing sedentary time corresponds with increasing mortality rate [12-15]. Sedentary behaviour has significant economic costs. Sedentary behaviour was estimated to cost the United Kingdom (UK) National Health Service (NHS) $£ 0.7$ billion in 2016-2017 [16]. A total of 69,276 deaths could potentially have been avoided in the UK if sedentary behaviour was eliminated [16]. In light of these findings, 2019 UK physical activity guidelines state that through all stages of life, individuals should minimise their sedentary behaviour, and break up periods of sedentary behaviour where possible [5].

Previous studies have examined levels of sedentary behaviour among other professions $[17,18]$, however General Practice is a different working environment, with different challenges and opportunities from other professions, even within the field of healthcare. Primary care has been described as "the cornerstone" of the NHS, providing over 300 million patient consultations per year $[19,20]$. This enables General Practitioners (GPs) to play an important role in both primary and secondary prevention, by providing evidence-based lifestyle guidance to patients. GPs can reinforce important public health messages among their patients, making them more specific, individualised and personally relevant. Numerous studies have demonstrated that GPs who are more physically active are more likely to recommend physical activity to their patients [21-30]. Patients are also more likely to make healthy lifestyle changes recommended by their doctor if they believe their doctor follows the health advice themselves [31-34]. It could therefore be argued that reducing sedentary behaviour and increasing physical activity among GPs could lead to health benefits for both GPs themselves, at an individual level, and their patients, at a population level. Within the context of day-to-day General Practice, this would primarily involve interrupting or replacing prolonged periods of sitting with physical activity. One example is the use of active workstations, such as standing desks, combined with short breaks for physical activity, such as "exercise snacks". Sitting while using a computer or telephone is a form of sedentary behaviour ( $\leq 1.5$ METs), whereas standing while using a computer or telephone is a form of light physical activity (1.8 METs) [35]. Reducing sedentary behaviour among GPs, by replacing sedentary behaviour with physical activity, could therefore play a vital role, as part of a multifaceted approach alongside public health initiatives and changes to the built environment, in ensuring a culture shift away from an increasingly sedentary society, towards an increasingly physically active society.

The aim of this systematic review is to identify the current levels of sedentary behaviour among GPs. The review examines and synthesises how sedentary behaviour has been measured in the primary care literature.

\section{Methods}

This systematic review was conducted according to Preferred Reporting Items for Systematic Reviews and Meta-Analyses (PRISMA) guidance. The focus of this review was the identification of peer-reviewed, published articles which reported sedentary behaviour among GPs (including family doctors and primary care doctors and/ or physicians). Searches were performed using Medline ${ }^{\circ}$, Embase ${ }^{\circ}$, PscycINFO and Web of Science databases, with assistance from a medical librarian (last search performed on 29th January 2020). Given the low number of 
eligible studies identified, a subsequent search of the Cochrane Library database, as well grey literature within thesis, dissertation and clinic trial databases (OpenGrey, EThOS, DART-Europe, OATD, International Clinical Trials Registry Platform) was performed, with handsearching of reference lists of screened studies. Terms relating to General Practice and sedentary behaviour were combined using keywords, title, or abstract, with appropriate alternative spellings and truncation symbols. Due to the small number of available studies identified, a narrative synthesis was undertaken of the included studies.

\section{Study selection}

Detailed searches were performed within Medline ${ }^{\circ}$, Embase, PscycINFO, Web of Science and Cochrane Library databases, as well grey literature within thesis, dissertation and clinic trial databases (OpenGrey, EThOS, DART-Europe, OATD, International Clinical Trials Registry Platform), supplemented by hand-searching of reference lists of screened studies. Two authors independently screened titles and abstracts of publications retrieved from the completed searches, once duplicates were removed. A third author was available to resolve any conflicts in study inclusion. Articles were discarded if they did not meet the inclusion criteria, with a record kept of the number discarded at each stage and reason for exclusion. Although no language restrictions were made, all included papers were written in English. Extracted data included populations and settings, sample sizes and response rates, methodological issues, eligibility criteria, study design, and definitions and measures. The terms 'general practitioner', 'GP', 'family physician', and 'family practitioner' were all considered to relate to the same discipline. For the purposes of this study, the term used is 'general practitioner' or 'GP'.

\section{Data synthesis and quality assessment}

Data were synthesised in terms of reported hours of sedentary behaviour among study participants. Objective criteria were used to assess quality and risk of bias within recruitment, sample population, reliability and validity of outcome measures according to the Newcastle-Ottawa quality assessment scale adapted for cross sectional studies, as previously described by Herzog et al. [36] and Luchini et al. [37] (additional file 1).

\section{Results}

One thousand seven hundred and seven studies were identified after duplicates were removed. After screening titles and abstracts, 1673 were excluded. Out of 34 full text articles which were reviewed, only 2 measured sedentary behaviour among GPs, both of which were included in the final review (Fig. 2). Applying the Newcastle-Ottawa quality assessment scale adapted for cross sectional studies, both included studies were of satisfactory methodological quality (Table 1). The main reasons for study exclusion were studies not taking place in the General Practice setting, studies examining patients, not GPs themselves, and studies not examining sedentary behaviour. Although 5 studies initially appeared to relate to levels of sedentary behaviour among GPs, 3 of these were excluded as they used an incorrect, imprecise or outdated definition of sedentary behaviour [22, 23, 40]. Brotons et al. [22], Cornuz et al. [23] and Jonsdottir et al. [40] did not clearly state how they defined GPs as being sedentary. It appears that they were instead referring to GPs who did not exercise regularly, who would currently be defined as being physically inactive (ie. not meeting physical activity recommendations). A description of the studies included in the final review is displayed in Table 2.

The first study included was a cross-sectional survey of all GP trainees and GP trainers in the Republic of Ireland by Keohane et al. [41]. In total there were 219 eligible respondents [41]. The primary aim of the study was to explore levels of physical activity among Irish GPs and GP trainees, with an additional aim of investigating their perceived barriers to exercise [41]. The study used the selfadministered International Physical Activity Questionnaire (IPAQ) to assess levels of physical activity [41-43]. Within the short form of the IPAQ, although it is primarily a tool used for self-estimation of physical activity, there is a question relating to sedentary behaviour [42]. Participants are asked about the time they spend sitting on a weekday while at work, at home, while doing course work and during leisure time, which may include time spent sitting at a desk, visiting friends, reading or sitting or lying down to watch television [42]. In the study by Keohane et al., $60 \%$ reported spending in excess of $7 \mathrm{~h}$ sitting each day, $24 \%$ between 4 and $7 \mathrm{~h}$, and $16 \%$ less than or equal to $4 \mathrm{~h}$ [41]. There was no significant difference in sitting time between male and female respondents $(p=0.61)$ [41]. There was, however, a statistically significant difference in sitting time reported by trainees working in hospital compared to those working in GP Practices $(p<0.05)$ and between qualified GPs and GP trainees $(p<0.05)$ [41]. There was no specific detail of the mean levels of sitting time within each of these groups [41]. It is likely that trainees working in the hospital setting were overall less sedentary than those working in the GP Practice setting, and therefore GP trainees were overall less sedentary than qualified GPs, however, in the absence of sufficient data we cannot say this with certainty [41].

The second study included was a cross-sectional survey of female GPs in Estonia [44]. There were 198 responses included in the analysis [44]. The aim of this study was to explore physical activity among Estonian GPs, as well as their physical activity counselling 


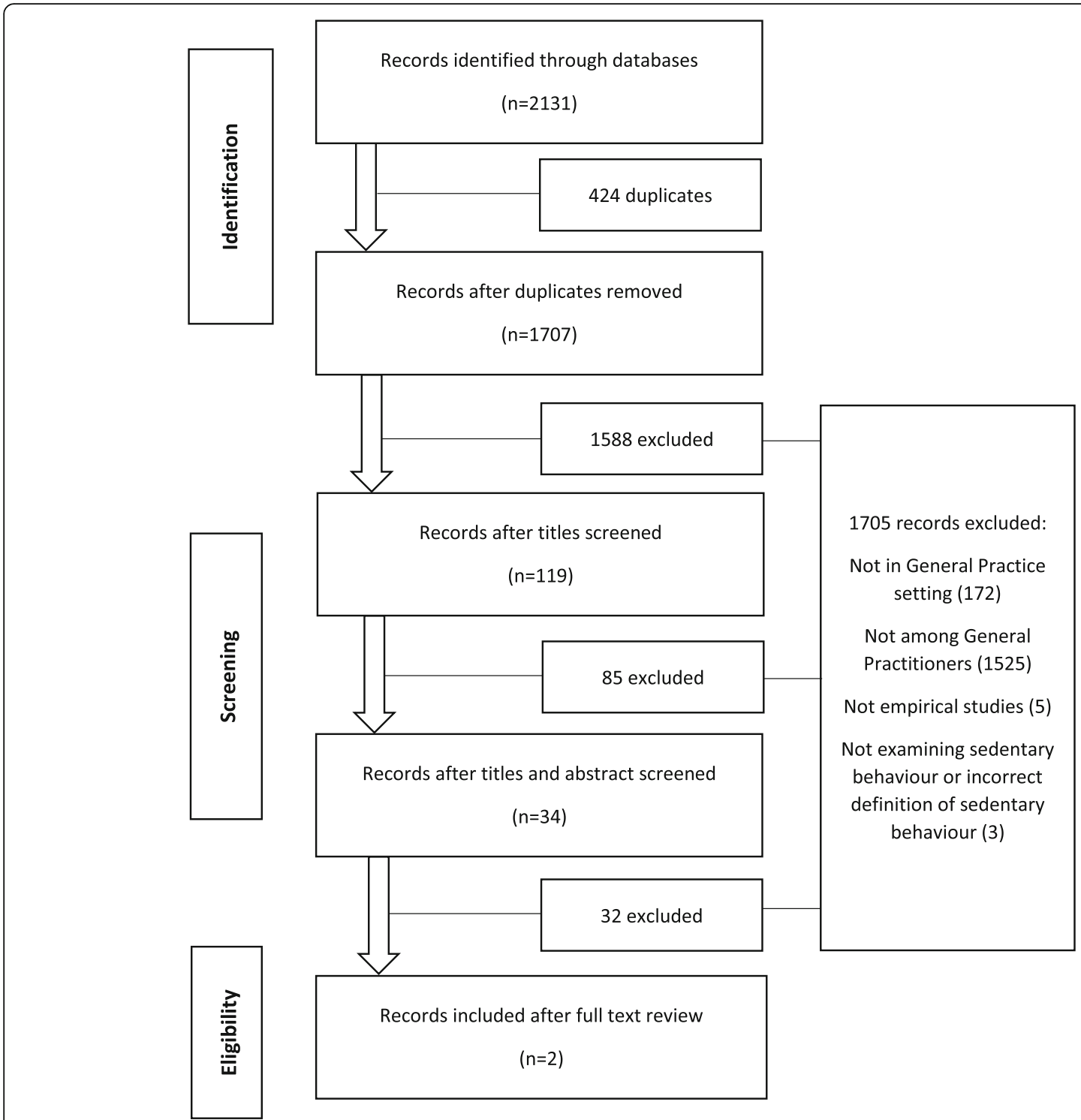

Fig. 2 Flow diagram for identification, screening, eligibility, and inclusion of papers for review

practices [44]. Only female GPs were included, as $95 \%$ of GPs in Estonia were female at the time of the study [44]. The self-administered International Physical Activity Questionnaire (IPAQ) short form was translated into Estonian and used to assess self-reported levels of physical activity, as well as sitting time [42-44]. The mean amount of daily sitting time was $6 \mathrm{~h}$ and $36 \mathrm{~min}$, with $56 \%$ sitting for over $6 \mathrm{~h}$ per day [44]. Levels of physical activity were compared between those who reported sitting less than $6 \mathrm{~h}$ per day and those who reported sitting more than $6 \mathrm{~h}$ per day [44]. Although those who reported sitting less than $6 \mathrm{~h}$ per day appeared to be slightly more physically active, this was not statistically significant $(p=0.207)$ [44].

\section{Discussion}

\section{Overview}

This is the first systematic review of the levels of sedentary behaviour among GPs. One thousand seven hundred and seven studies were identified from our search criteria, with 2 studies included in the final review. Included studies were cross-sectional, with self-reporting of sedentary behaviour in hours and minutes. Both studies were of satisfactory methodological quality, however both had risk of bias and lack of objectivity. They both focused primarily on levels of physical activity among GPs, using the International Physical Activity Questionnaire (IPAQ). In the IPAQ, just one question concerns sedentary behaviour, where participants are asked to 


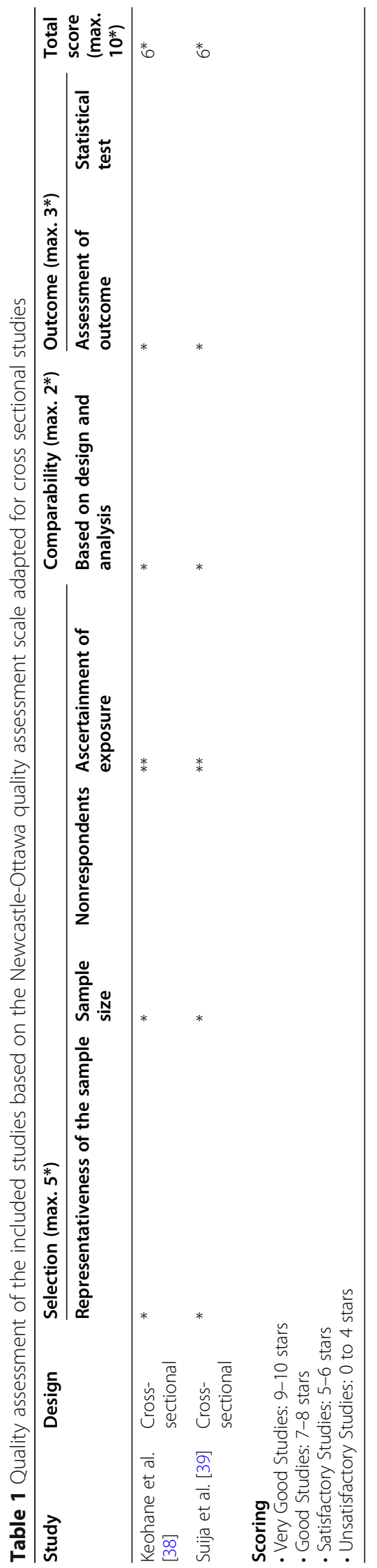


Table 2 Description of Included Studies

\begin{tabular}{|c|c|c|c|c|c|c|c|}
\hline Author & Country & $\begin{array}{l}\text { Number of } \\
\text { participants }\end{array}$ & $\begin{array}{l}\text { Study } \\
\text { design }\end{array}$ & Criteria for inclusion & Assessment method & Objectivity & Quality \\
\hline $\begin{array}{l}\text { Keohane } \\
\text { et al. }\end{array}$ & Ireland & 219 & $\begin{array}{l}\text { Cross- } \\
\text { sectional }\end{array}$ & $\begin{array}{l}\text { GP Trainers and GP } \\
\text { Trainees }\end{array}$ & $\begin{array}{l}\text { Self-reported } \\
\text { questionnaire }\end{array}$ & $\begin{array}{l}\text { Non- } \\
\text { objective }\end{array}$ & Satisfactory \\
\hline Suija et al. & Estonia & 198 & $\begin{array}{l}\text { Cross- } \\
\text { sectional }\end{array}$ & Female GPs & $\begin{array}{l}\text { Self-reported } \\
\text { questionnaire }\end{array}$ & $\begin{array}{l}\text { Non- } \\
\text { objective }\end{array}$ & Satisfactory \\
\hline
\end{tabular}

estimate how much time they spent sitting on a week day [42]. Both studies may have been affected by selection bias, whereby survey participants may have been less sedentary and more physically active than those who did not respond. The study by Suija et al. questioned only female GPs, so findings may not be valid among male GPs, however there were no significant differences between males and females in the study by Keohane et al. [44]. As responses were self-estimated, as oppose to objectively measured findings, participants may also have either overestimated or underestimated their true levels of physical activity and sedentary behaviour. Both studies used validated questionnaires for the selfassessment of physical activity and sedentary behaviour. There is some debate regarding the validity of selfestimated, compared to objectively measured, findings of sedentary behaviour and physical activity $[38,39,42,43$, 45-49]. It is widely acknowledged that objective data (such as that obtained using accelerometers or pedometers) has higher validity than self-estimation of sedentary behaviour and physical activity, with self-estimation shown to typically underestimate sedentary behaviour by approximately $1.74 \mathrm{~h}$ per day $[45,46,50]$. With the recent increase in remote consulting among GPs as a result of the COVID-19 pandemic, GPs have less face-toface interaction with patients, with the majority of consultations now happening via telephone and video [51]. This opens up both challenges and opportunities for GPs regarding their levels of sedentary behaviour [52, 53]. It does, however, mean that GPs now have more in common with workers in other medical and non-medical environments, such as office and call centre workers, where interventions targeted at reducing levels of sedentary behaviour have had varying levels of success [54-58].

\section{Strengths and limitations}

Strengths of this systematic review were the use of a clearly defined search and study selection strategy, with double reviewing of all stages. Using a wide search strategy, with no exclusion based on language, supplemented by hand-searching of reference lists, allowed authors to identify as many eligible studies as possible. Despite this, just 2 eligible studies were identified, both in English. A limitation of this review is the lack of studies available in the area of sedentary behaviour among GPs. Sedentary behaviour is a novel and emerging area of research.
Although there has been an increasing volume of research examining sedentary behaviour in other settings, this study has identified a lack of research in the field of General Practice. Most studies in the General Practice setting appear to focus on either physical activity or sedentary behaviour of patients, not among GPs themselves.

\section{Conclusion}

In light of the established associations between sedentary behaviour, adverse health outcomes and mortality, GPs should consider their own levels of sedentary behaviour, as well as that of their patients. GPs can potentially be key protagonists in reducing sedentary behaviour among the general population by virtue of their position in the healthcare system, where they have significant levels of patient contact and opportunities for health promotion.

At present, there is a paucity of research examining current levels of sedentary behaviour among GPs. This systematic review identified just 2 papers assessing levels of sedentary behaviour among GPs, both of which used self-reported estimations [41, 44]. Given that GPs who are more physically active are more likely to recommend physical activity to their patients, and patients are more likely to make healthy lifestyle changes if they believe their doctor follows the health advice themselves, by reducing their sedentary behaviour and increasing their physical activity, GPs could play an important role in the development of a less sedentary and more physically active society [31-34]. There is therefore a clear need for more reliable and objective data to determine the current levels of sedentary behaviour among GPs, particularly in light of the increase in remote consulting as a result of the COVID-19 pandemic.

\section{Additional Files}

\footnotetext{
Additional file 1. Critical appraisal tool for cross-sectional studies. Modified from the Newcastle-Ottawa Quality Assessment Scale for Cohort Studies.
}

\section{Abbreviations}

COVID-19: Coronavirus disease 2019; GP: General Practitioner;

IPAQ: International Physical Activity Questionnaire; METs: Metabolic Equivalent of Tasks; NHS: National Health Service; PRISMA: Preferred Reporting Items for Systematic Reviews and Meta-Analyses 


\section{Acknowledgements}

We gratefully acknowledge the assistance of Richard Fallis, Subject Librarian for Medicine, Dentistry and Biomedical Sciences, Queen's University Medical Library, in providing guidance with the literature search for the systematic review.

\section{Authors' contributions}

RSM, NDH and NH were involved in the design and planning of the study. RSM carried out the data analysis and drafted the initial manuscript. NH assisted with redrafting the manuscript and all authors reviewed and approved the manuscript prior to submission.

\section{Funding}

RSM's study fees and maintenance come from Health and Social Care Research and Development Division, Public Health Agency's GP Academic Research Training Scheme and EAT/5332/19. The funding body had no role in the design of the study, the collection, analysis, and interpretation of data, or in writing the manuscript.

\section{Availability of data and materials}

The datasets used and analysed during the current study are available from the corresponding author following reasonable request.

\section{Ethics approval and consent to participate}

Not applicable.

\section{Consent for publication}

Not applicable: no details of any individuals are reported within the paper.

\section{Competing interests}

The authors declare that they have no competing interests.

Received: 2 June 2020 Accepted: 20 December 2020

Published online: 04 January 2021

\section{References}

1. Sedentary Behaviour Research Network. Letter to the editor: standardized use of the terms "sedentary" and "sedentary behaviours." Appl Physiol Nutr Metab. 2012;37(3):540-2.

2. Tremblay MS, Aubert S, Barnes JD, Saunders TJ, Carson V, Latimer-Cheung AE, et al. Sedentary Behavior Research Network (SBRN) - Terminology Consensus Project process and outcome. Int J Behav Nutr Phys Act. 2017; 14(1):75.

3. Jetté M, Sidney K, Blümchen G. Metabolic equivalents (METS) in exercise testing, exercise prescription, and evaluation of functional capacity. Clin Cardiol. 1990:13(8):555-65.

4. Caspersen CJ, Powell KE, Christenson GM. Physical activity, exercise, and physical fitness: definitions and distinctions for health-related research. Public Health Rep. 1985;100(2):126-31.

5. Davies SC, Atherton F, McBride M, Calderwood C. UK chief medical Officers' physical activity guidelines; 2019.

6. Morris JN, Heady JA, Raffle PAB, Roberts CG, Parks JW. Coronary heartdisease and physical activity of work. Lancet. 1953;262(6795):1053-7.

7. Morris JN, Heady JA, Raffle PAB, Roberts CG, Parks JW. Coronary heartdisease and physical activity of work. Lancet. 1953;262(6796):1111-20.

8. Paffenbarger RS Jr, Blair SN, Lee IM. A history of physical activity, cardiovascular health and longevity: the scientific contributions of Jeremy N Morris, DSC, DPH. FRCP Int J Epidemiol. 2001;30(5):1184-92.

9. Hamer M, Stamatakis E, Steptoe A. Dose-response relationship between physical activity and mental health: the Scottish health survey. $\mathrm{Br} J$ Sports Med. 2009:43(14):1111-4

10. Ravaglia G, Forti P, Lucicesare A, Pisacane N, Rietti E, Bianchin M, et al. Physical activity and dementia risk in the elderly. Find Prospect Italian Stud. 2008;70(19 Part 2):1786-94

11. Rovio S, Kåreholt I, Helkala E-L, Viitanen M, Winblad B, Tuomilehto J, et al. Leisure-time physical activity at midlife and the risk of dementia and Alzheimer's disease. Lancet Neurol. 2005;4(11):705-11.

12. Biswas A, Oh Pl, Faulkner GE, Bajaj RR, Silver MA, Mitchell MS, et al. Sedentary time and its association with risk for disease incidence, mortality, and hospitalization in adults: a systematic review and meta-analysis. Ann Intern Med. 2015;162(2):123-32.
13. Chau JY, Grunseit AC, Chey T, Stamatakis E, Brown WJ, Matthews CE, et al. Daily sitting time and all-cause mortality: a meta-analysis. PLoS One. 2013; 8(11):e80000.

14. Koster A, Caserotti P, Patel KV, Matthews CE, Berrigan D, Van Domelen DR, et al. Association of sedentary time with mortality independent of moderate to vigorous physical activity. PLoS One. 2012;7(6):e37696.

15. Katzmarzyk PT, Church TS, Craig CL, Bouchard C. Sitting time and mortality from all causes, cardiovascular disease, and cancer. Med Sci Sports Exerc. 2009:41(5):998-1005.

16. Heron L, O'Neill C, McAneney H, Kee F, Tully MA. Direct healthcare costs of sedentary behaviour in the UK. J Epidemiol Community Health. 2019;73(7): 625-9.

17. Reed JL, Prince SA. Women's heart health: a focus on nurses' physical activity and sedentary behaviour. Curr Opin Cardiol. 2018;33(5):514-20.

18. Kazi A, Duncan M, Clemes S, Haslam C. A survey of sitting time among UK employees. Occup Med. 2014;64(7):497-502.

19. NHS-England. NHS 5 Year Forward View - Primary Care 2017 [Available from: https://www.england.nhs.uk/five-year-forward-view/next-steps-on-the-nhsfive-year-forward-view/primary-care/.

20. Lewith $G$, Peters $D$, Manning C. Primary care is the cornerstone of our NHS. Bri J Gen Pract. 2016;66(653):604.

21. Abramson S, Stein J, Schaufele M, Frates E, Rogan S. Personal exercise habits and counseling practices of primary care physicians: a national survey. Clin J Sport Med. 2000;10(1):40-8.

22. Brotons $C$, Björkelund $C$, Bulc $M$, Ciurana R, Godycki-Cwirko M, Jurgova $E_{,}$ et al. Prevention and health promotion in clinical practice: the views of general practitioners in Europe. Prev Med. 2005;40(5):595-601.

23. Cornuz J, Ghali WA, Di Carlantonio D, Pecoud A, Paccaud F. Physicians attitudes towards prevention: importance of intervention-specific barriers and physicians health habits. Fam Pract. 2000;17(6):535-40.

24. Duclos M, Coudeyre E, Ouchchane L. General Practitioners' Barriers to Physical Activity Negatively Influence Type 2 Diabetic Patients' Involvement in Regular Physical Activity. Diabetes Care. 2011;34(7):e122.

25. Frank E, Segura C, Shen H, Oberg E. Predictors of Canadian physicians' prevention counseling practices. Canad J Public Health. 2010;101(5):390-5.

26. Klein D, Guenther C, Ross S. Do as I say, not as I do. Lifestyles and counseling practices of physician faculty at the University of Alberta 2016; 62(7):e393-e3e9.

27. Lobelo F, de Quevedo IG. The evidence in support of physicians and health care providers as physical activity role models. Am J Lifestyle Med. 2016; 10(1):36-52

28. Lobelo F, Duperly J, Frank E. Physical activity habits of doctors and medical students influence their counselling practices. Br J Sports Med. 2008;43(2): 89-92.

29. Shahar DR, Henkin Y, Rozen GS, Adler D, Levy O, Safra C, et al. A controlled intervention study of changing health-providers' attitudes toward personal lifestyle habits and health-promotion skills. Nutrition. 2009;25(5):532-9.

30. Stanford FC, Durkin MW, Stallworth JR, Powell CK, Poston MB, Blair SN. Factors that Influence Physicians' and Medical Students' Confidence in Counseling Patients About Physical Activity. J Prim Prev. 2014;35(3):193-201.

31. Frank E, Breyan J, Elon L. Physician disclosure of healthy personal behaviors improves credibility and ability to motivate. Arch Fam Med. 2000;9(3):287-9.

32. Fraser S, Leveritt M, Ball L. Patients' perceptions of their general practitioner's health and weight influences their perceptions of nutrition and exercise advice received. J Prim Health Care. 2013;5(4):301-7.

33. Lemaire JB, Ewashina D, Polachek AJ, Dixit J, Yiu V. Understanding how patients perceive physician wellness and its links to patient care: a qualitative study. PLoS One. 2018;13(5):e0196888.

34. Puhl RM, Gold JA, Luedicke J, Depierre JA. The effect of physicians' body weight on patient attitudes: implications for physician selection, trust and adherence to medical advice. Int J Obes. 2013;37(11):1415-21.

35. Ainsworth BE, Haskell WL, Herrmann SD, Meckes N, Bassett DR Jr, TudorLocke C, et al. 2011 compendium of physical activities: a second update of codes and MET values. Med Sci Sports Exerc. 2011;43(8):1575-81.

36. Herzog R, Álvarez-Pasquin MJ, Díaz C, Del Barrio JL, Estrada JM, Gil Á. Are healthcare workers' intentions to vaccinate related to their knowledge, beliefs and attitudes? A systematic review. BMC Public Health. 2013;13(1):154.

37. Luchini C, Stubbs B, Solmi M, Veronese N. Assessing the quality of studies in meta-analyses: advantages and limitations of the Newcastle Ottawa scale. World J Meta-Analysis. 2017;5(4):80. 
38. Chastin SF, Culhane B, Dall PM. Comparison of self-reported measure of sitting time (IPAQ) with objective measurement (activPAL). Physiol Meas. 2014;35(11):2319-28.

39. Kurtze N, Rangul V, Hustvedt B-E. Reliability and validity of the international physical activity questionnaire in the Nord-Trøndelag health study (HUNT) population of men. BMC Med Res Methodol. 2008:8(1):63.

40. Jonsdottir IH, Borjesson M, Ahlborg G. Healthcare workers' participation in a healthy-lifestyle-promotion project in western Sweden. BMC Public Health. 2011;11:448.

41. Keohane DM, McGillivary NA, Daly B. Physical activity levels and perceived barriers to exercise participation in Irish general practitioners and general practice trainees. Ir Med J. 2018;111(2):690.

42. Craig C, Marshall A, Sjöström M, Bauman A, Booth M, Ainsworth B, et al. International physical activity questionnaire: 12 -country reliability and validity. Med Sci Sports Exerc. 2003:35(8):1381-95.

43. Hagstromer M, Oja P, Sjostrom M. The international physical activity questionnaire (IPAQ): a study of concurrent and construct validity. Public Health Nutr. 2006;9(6):755-62

44. Suija K, Pechter U, Maaroos J, Kalda R, Ratsep A, Oona M, et al. Physical activity of Estonian family doctors and their counselling for a healthy lifestyle: a cross-sectional study. BMC Fam Pract. 2010;11:48.

45. Guo W, Key TJ, Reeves GK. Accelerometer compared with questionnaire measures of physical activity in relation to body size and composition: a large cross-sectional analysis of UK biobank. BMJ Open. 2019;9(1):e024206.

46. Dall P, Coulter E, Fitzsimons C, Skelton D, Chastin S. TAxonomy of selfreported sedentary behaviour tools (TASST) framework for development, comparison and evaluation of self-report tools: content analysis and systematic review. BMJ Open. 2017;7(4):e013844.

47. Prince S, Leblanc A, Colley R, Saunders T. Measurement of sedentary behaviour in population health surveys: a review and recommendations. PeerJ. 2017;5:e4130.

48. Rosenberg DE, Bull FC, Marshall AL, Sallis JF, Bauman AE. Assessment of sedentary behavior with the international physical activity questionnaire. J Phys Act Health. 2008;5(s1):S30-44.

49. Scholes S, Bridges S, Ng Fat L, Mindell JS. Comparison of the physical activity and sedentary behaviour assessment questionnaire and the shortform international physical activity questionnaire: an analysis of health survey for England data. PLoS One. 2016;11(3):e0151647.

50. Prince SA, Cardilli L, Reed JL, Saunders TJ, Kite C, Douillette K, et al. A comparison of self-reported and device measured sedentary behaviour in adults: a systematic review and meta-analysis. Int J Behav Nutr Phys Act. 2020;17(1):31.

51. Joy M, McGagh D, Jones N, Liyanage H, Sherlock J, Parimalanathan V, et al. Reorganisation of primary care for older adults during COVID-19: a crosssectional database study in the UK. Br J Gen Pract. 2020;70(697):e540-e7.

52. Mayne R. Remote consulting during and post COVID-19: an opportunity to move more? InnovAiT. 2020;13(12):754-5.

53. Brockhurst I, Wong J, Garr H, Batt ME. Physical activity in practice: why and how to get GPs moving. Br J Gen Pract. 2019;69(683):276-7.

54. Edwardson CL, Yates T, Biddle SJH, Davies MJ, Dunstan DW, Esliger DW, et al. Effectiveness of the stand more AT (SMArT) work intervention: cluster randomised controlled trial. BMJ. 2018;363:k3870.

55. Morelli JN. Radiologist, walk thyself. J Am Coll Radiol. 2012;9(5):309-10

56. Prince SA, Saunders TJ, Gresty K, Reid RD. A comparison of the effectiveness of physical activity and sedentary behaviour interventions in reducing sedentary time in adults: a systematic review and meta-analysis of controlled trials. Obes Rev. 2014:15(11):905-19.

57. Gardner B, Smith L, Lorencatto F, Hamer M, Biddle SJ. How to reduce sitting time? A review of behaviour change strategies used in sedentary behaviour reduction interventions among adults. Health Psychol Rev. 2016;10(1):89-112.

58. Stephens SK, Eakin EG, Clark BK, Winkler EAH, Owen N, Lamontagne AD, et al. What strategies do desk-based workers choose to reduce sitting time and how well do they work? Findings from a cluster randomised controlled trial. Int J Behav Nutr Phys Act. 2018;15(1):98.

\section{Publisher's Note}

Springer Nature remains neutral with regard to jurisdictional claims in published maps and institutional affiliations.

\section{Ready to submit your research? Choose BMC and benefit from:}

- fast, convenient online submission

- thorough peer review by experienced researchers in your field

- rapid publication on acceptance

- support for research data, including large and complex data types

- gold Open Access which fosters wider collaboration and increased citations

- maximum visibility for your research: over $100 \mathrm{M}$ website views per year

At BMC, research is always in progress.

Learn more biomedcentral.com/submissions 